\section{(- OPEN ACCESS}

\title{
Out-of-hospital initiation of hypothermia in ST- segment elevation myocardial infarction: a randomised trial
}

\author{
Christoph Testori, ${ }_{1}^{1}$ Dietrich Beitzke, ${ }_{1}^{2}$ Andreas Mangold, ${ }_{1}^{3}$ Fritz Sterz, ${ }_{1}$ Christian Loewe, ${ }^{2}$ \\ Christoph Weiser, ${ }_{1}^{1}$ Thomas Scherz, ${ }^{3}$ Harald Herkner, ${ }_{1}^{1}$ Irene Lang ${ }^{3}$
}

\begin{abstract}
- Additional material is published online only. To view please visit the journal online (http://dx.doi.org/10.1136/ heartjnl-2018-313705).

${ }^{1}$ Department of Emergency Medicine, Medical University of Vienna, Vienna, Austria 2Division of Cardiovascular and Interventional Radiology, Department of Biomedical Imaging and Image-Guided Therapy, Medical University of Vienna, Vienna, Austria ${ }^{3}$ Division of Cardiology, Department of Internal Medicine II, Medical University of Vienna, Vienna, Austria
\end{abstract}

\section{Correspondence to}

Dr Fritz Sterz, Department of Emergency Medicine, Medical University of Vienna, Vienna 1090,Austria; fritz.sterz@ meduniwien.ac.at

Received 6 June 2018 Revised 15 September 2018 Accepted 19 September 2018 Published Online First 25 October 2018

\section{A
O
hyp
inf
ca
a
tr
th
co
th}

\section{ABSTRACT}

Objective To evaluate the effect of prereperfusion hypothermia initiated in the out-of-hospital setting in awake patients with ST-segment elevation myocardial infarction (STEMI) on myocardial salvage measured by cardiac MRI (CMR).

Methods Hypothermia was initiated within 6 hours of symptom onset by the emergency medical service with surface cooling pads and cold saline, and continued in the cath lab with endovascular cooling (target temperature: $\leq 35^{\circ} \mathrm{C}$ at time of reperfusion). Myocardial salvage index (using CMR) was compared in a randomised, controlled, open-label, endpoint blinded trial to a not-cooled group of patients at day $4 \pm 2$ after the event.

Results After postrandomisation exclusion of 19 patients a total of 101 patients were included in the intention-to-treat analysis (control group: $n=54$; hypothermia group: $n=47)$. Target temperature was reached in 38/47 patients (81\%) in the intervention group. Study-related interventions resulted in a delay in time from first medical contact to reperfusion of 14 min (control group 89 \pm 24 min; hypothermia group $103 \pm 21 \mathrm{~min} ; \mathrm{p}<0.01)$. Myocardial salvage index was $0.37( \pm 0.26)$ in the control group and $0.43( \pm 0.27)$ in the hypothermia group $(p=0.27)$. No differences in cardiac biomarkers or clinical outcomes were found. In a CMR follow-up 6 months after the initial event no significant differences were detected.

Conclusion Out-of-hospital induced therapeutic hypothermia as an adjunct to primary percutaneous coronary intervention did not improve myocardial salvage in patients with STEMI.

Trial registration number NCT01777750

\section{INTRODUCTION}

Emergency revascularisation of the infarct-related artery by primary percutaneous coronary intervention (PCI) ${ }^{1}$ is the treatment of choice in ST-segment elevation myocardial infarction (STEMI). Infarct size is one of the main predictors of outcome, and reducing infarct size is an important objective of current research. ${ }^{2}$ Reperfusion itself aggravates myocardial damage through several mechanisms subsummarised as reperfusion injury, ${ }^{3-5}$ accounting for up to $50 \%$ of final infarct size. ${ }^{6}$ Reperfusion injury is a multifactorial event which is still poorly understood. ${ }^{7}$ The underlying mechanisms appear to involve reperfusion injury salvage kinase and glycogen synthase kinase 3 beta, ${ }^{8}$ and affect mitochondrial permeability transition pore, a protein that is formed in the inner membrane of undercellular stress, increasing mitochondrial permeability. As far as is currently known mild therapeutic hypothermia (MTH) interferes with these processes resulting in superior outcome in various models of ischaemia/reperfusion injury. ${ }^{9-11}$

The significance of MTH in STEMI is still a matter of debate. ${ }^{12}$ One critical feature extrapolated from animal studies and clinical trials is that MTH should be initiated prior to revascularisation with a target temperature of $35^{\circ} \mathrm{C}$ and below. ${ }^{13} \mathrm{~A}$ small feasibility and safety study in 2010 showed a significant reduction of infarct size in relation to myocardium at risk. ${ }^{14}$ In the following CHILL-MI multicentre trial benefit of cooling was only found in a subgroup of patients who presented early with anterior wall myocardial infarction. ${ }^{15}$

We have been able to demonstrate the feasibility of a strategic protocol for out-of-hospital initiation of hypothermia at the time of first medical contact in patients with STEMI. ${ }^{16}$ To test the efficacy and safety of out-of-hospital initiation of hypothermia in patients with STEMI we designed a single-centre, randomised, endpoint blinded study. A strategic combination of surface, intravenous and endovascular cooling for induction and maintenance of prereperfusion mild hypothermia was used. We hypothesised that therapeutic hypothermia initiated in the out-of-hospital setting as an adjunct to standard therapy is able to improve myocardial salvage.

\section{METHODS}

This study was performed as a randomised, controlled, open-label, endpoint blinded trial and was conducted according to the principles of the Declaration of Helsinki (version 5, 2008). The requirement of informed consent during the acute phase was waived in accordance with the ethical standards of the local institutional review board. Subjects were informed about the aims of the study prior to inclusion. After PCI and a stabilisation phase, each patient had to sign informed consent for further participation.

\section{Population}

Men and women between 18 and 75 years presenting with at least $30 \mathrm{~min}$ of continuous typical chest pain, with anterior or inferior STEMI
To cite: Testori C, Beitzke $D_{1}$ Mangold A, et al. Heart 2019;105:531-537. 
and ST-segment elevations $>0.2 \mathrm{mV}$ in two contiguous leads and a duration of symptoms less than 6 hours prior to presentation to the emergency medical service, were included. The possibility of immediate transfer to the catheterisation laboratory for PCI was mandatory for inclusion. Exclusion criteria were cardiac arrest, a tympanic temperature below $35^{\circ} \mathrm{C}$ at presentation, a history of myocardial infarction or $\mathrm{PCI} /$ coronary artery bypass grafting, chronic heart failure (New York Heart Association II-IV) and acute heart failure (Killip class II-IV). Furthermore, patients treated with thrombolytic agents, clinical signs of infection, end-stage kidney disease, hepatic failure, recent stroke, haematological dyscrasias, oral anticoagulant treatment or severe pulmonary disease were excluded. Patients with a known allergy to meperidine, buspirone, or using monoamine oxidase inhibitors, as well as women of childbearing potential were excluded.

\section{Randomisation}

Included patients were randomly allocated to either MTH or control in a 1:1 ratio. The randomisation list was computer generated in a permuted block fashion and transferred to a sequence of sealed, opaque, consecutively numbered envelopes before study start. Randomisation was performed by opening subsequent envelopes by the emergency physician on scene.

\section{Targeted temperature management and antishivering management}

To prevent shivering, patients randomised to $\mathrm{MTH}$ received $30 \mathrm{mg}$ of oral buspirone (Busp, Hexal, Germany). Meperidine (Alodan, GL Pharma, Austria) was administered as a loading dose of $1 \mathrm{mg} / \mathrm{kg}$ followed by a continuous drip at a rate of $30 \mathrm{mg} /$ hour at the cath lab. In addition, a bolus of $20 \mathrm{mg}$ meperidine was administered in case of shivering followed by an increase of the continuous drip by $5 \mathrm{mg} /$ hour. Temperature management was initiated in the prehospital setting by the administration of cold saline $(10 \mathrm{~mL} / \mathrm{kg}$ for anterior STEMI; $20 \mathrm{~mL} / \mathrm{kg}$ for inferior STEMI) followed by the application of surface cooling pads (EMCOOLS Flex.Pad, EMCOOLS Emergency Medical Cooling Systems, Pfaffstätten, Austria) on the patients' back, thorax, abdomen and thighs. In the cath lab, an endovascular cooling catheter (Accutrol 14Fr catheter and InnerCool RTx endovascular console; ZOLL Medical, Chelmsford, MA, USA) was placed into the inferior vena cava via the femoral vein, with the tip at the level of the diaphragm. The target temperature was set to $34^{\circ} \mathrm{C}$. Core temperature was assessed during endovascular cooling by the integrated temperature sensor at the tip of the cooling catheter. At all other time points, temperature was measured by an infrared tympanic thermometer (Ototemp LighTouch, Exergen, MA, USA). After placement of the cooling catheter, coronary angiography and PCI were performed. The target temperature of $34^{\circ} \mathrm{C}$ was maintained for $60 \mathrm{~min}$ after reperfusion. Thereafter, patients were allowed to rewarm passively. After reaching a temperature of $36^{\circ} \mathrm{C}$ the cooling catheter was removed.

\section{Cardiac MRI}

To assess left ventricular (LV) function (\%), infarct size (mL) and myocardial salvage index (MSI), cardiac MRI (CMR) was performed $4 \pm 2$ days after PCI using a $1.5 \mathrm{~T}$ system (Avanto Fit, Siemens Medical Systems, Erlangen Germany). CMR was performed according to an established, standardised protocol focused on infarct-related parameters described elsewhere. ${ }^{17}$ For late gadolinium enhancement (LGE) $0.15 \mathrm{~mL} / \mathrm{kg}$ gadobutrol $(0.1 \mathrm{mmol} / \mathrm{mL})$ (Gadovist, Bayer) was injected.

Image postprocessing was performed by an experienced cardiovascular radiologist blinded to the randomisation results using a dedicated CMR postprocessing software package (QMass, Medis, Leiden, Netherlands). Standardised methods for postinfarct imaging were applied, including evaluation of cardiac function, infarct size and MSI ((Area at risk - Infarct size)/Area at risk). ${ }^{17} 18$

CMR was performed $195 \pm 15$ days after PCI using the same protocol as the initial CMR without assessment of the MSI.

\section{Endpoints}

Primary endpoint was MSI by CMR on day $4 \pm 2$ with an index of 1.0 indicating maximum treatment success. An index of 0.0 indicates complete treatment failure. We analysed MSI for predefined subgroups of anterior and inferior infarcts separately. Secondary CMR endpoints were LV ejection fraction (\%), LV end-diastolic volume $(\mathrm{mL})$, infarct size in relation to LV myocardium (\%),

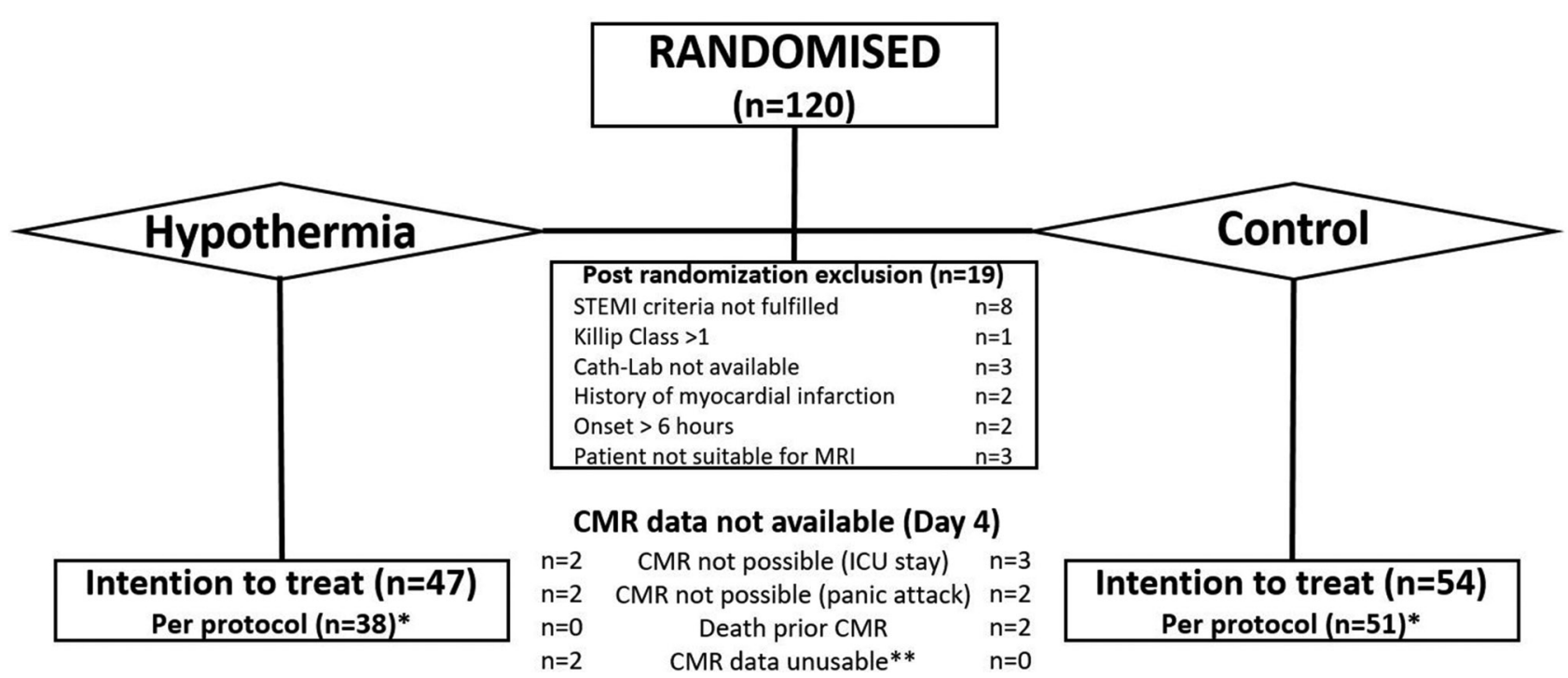

Figure 1 Flow chart of patient randomisation. *Reasons for protocol deviation were: target temperature not reached (hypothermia group: $\mathrm{n}=9$ ), death prior to cath lab (control group: $n=2$ ) and abortion of percutaneous coronary intervention ( $\mathrm{PCl}$; control group: $\mathrm{n}=1$ ). ${ }^{* *} \mathrm{CMR}$ data not analysable for T2-weighed CMR images. CMR, cardiac MRI; ICU, intensive care unit; STEMI, ST-segment elevation myocardial infarction. 
Table 1 Baseline characteristics

\begin{tabular}{|c|c|c|}
\hline & Control $(n=54)$ & Hypothermia $(n=47)$ \\
\hline Age, years (SD) & $55( \pm 12)$ & $58( \pm 10)$ \\
\hline Female gender, n (\%) & $10(19)$ & $10(21)$ \\
\hline Hypertension, n (\%) & $25(46)$ & $13(28)$ \\
\hline Diabetes, n (\%) & $10(19)$ & $5(11)$ \\
\hline Dyslipidaemia, n (\%) & $17(32)$ & $10(21)$ \\
\hline Current smoker, n (\%) & $30(56)$ & $26(55)$ \\
\hline Familial history of CAD, n (\%) & $12(22)$ & $12(25)$ \\
\hline Obesity, n (\%) & $19(35)$ & $10(21)$ \\
\hline Weight, kg (SD) & $89( \pm 18)$ & $82( \pm 20)$ \\
\hline Body mass index $\left(\mathrm{kg} / \mathrm{m}^{2}\right)$, mean (SD) & $29.3( \pm 4.9)$ & $27.1( \pm 5.5)$ \\
\hline \multicolumn{3}{|l|}{ Previous medication } \\
\hline Acetylsalicylic acid, n (\%) & $6(11)$ & $1(2)$ \\
\hline Beta blocker, n (\%) & $7(13)$ & $4(9)$ \\
\hline ACE-I/ARB, n (\%) & $11(20)$ & $8(17)$ \\
\hline Statin, $n(\%)$ & $12(22)$ & $3(6)$ \\
\hline Initial sinus rhythm, n (\%) & $49(90)$ & $44(94)$ \\
\hline Anterior wall infarction, $\mathrm{n}(\%)$ & $25(46)$ & $27(57)$ \\
\hline \multicolumn{3}{|l|}{ Emergency therapy } \\
\hline Acetylsalicylic acid, n (\%) & $54(100)$ & $47(100)$ \\
\hline Heparin, n (\%) & $54(100)$ & $47(100)$ \\
\hline Prasugrel/ticagrelor & $54(100)$ & $47(100)$ \\
\hline Nitroglycerin, n (\%) & $12(22)$ & $9(19)$ \\
\hline Beta blocker, n (\%) & $3(6)$ & $0(0)$ \\
\hline \multicolumn{3}{|l|}{ Infarct-related artery } \\
\hline$L A D^{*}, n(\%)$ & $24(45)$ & $28(60)$ \\
\hline Circumflex artery, n (\%) & $4(7)$ & $3(6)$ \\
\hline Right coronary artery, $\mathrm{n}(\%)$ & $25(46)$ & $16(34)$ \\
\hline Unknown, n (\%) & $1(2)$ & $0(0)$ \\
\hline Multivessel disease, n (\%) & $31(59)$ & $22(47)$ \\
\hline Initial TIMIt 0/1, n (\%) & $43(81)$ & $34(72)$ \\
\hline
\end{tabular}

No statistically significant difference between baseline variables (except for previous use of statins; $\mathrm{p}=0.03$ ).

* Left anterior descending artery

tThrombolysis in myocardial infarction grade flow.

ACE-I, ACE inhibitor; ARB, angiotensin receptor blocker; $C A D$, coronary artery

disease; LAD, left anterior descending artery.

myocardium at risk $(\mathrm{mL})$ and microvascular obstruction $(\mathrm{mL})$. In the second CMR on day $195 \pm 15$ ejection fraction (\%), LV end-diastolic volume $(\mathrm{mL})$ and infarct size $(\mathrm{mL})$ were assessed. Endpoints were analysed using the intention-to-treat set. The primary endpoint and all secondary CMR endpoints were analysed based on a per-protocol set as well. This set consists of all treated patients who did not violate the protocol in a way that might influence the evaluation of the effect of cooling on the primary endpoint (ie, temperature of maximum $35.0^{\circ} \mathrm{C}$ at reperfusion, CMR performed on day 4 \pm 2 ). Levels of troponin $\mathrm{T}$ and creatine kinase were measured at the time of first medical contact, on admission, 1 hour, and 6, 12, 24, 36 and 48 hours after reperfusion. N-terminal pro-brain natriuretic peptide was analysed on admission and on days 4 and 195. Clinical endpoints were collected up to day $45 \pm 15$ including death, emergency revascularisation or coronary bypass grafting, malignant arrhythmias, stroke, heart failure, pneumonia or sepsis, major bleeding and any cause of hospital admission.

\section{Statistical analysis}

We designed our study to detect an absolute difference in MSI by $20 \%$ at a type I error rate of 0.05 with $80 \%$ power and an assumed MSI of 0.45 in the control group. To allow for missing data or inadequate inclusion we increased the sample size from 93 to 120 patients.

Categorised data are presented as absolute count and relative frequency, and continuous data as mean $\pm S D$ after checking for normal distribution or as median and IQR if not normally distributed. We assessed randomisation success by tabulating baseline variables of the intervention group versus the control group.

We compared the primary outcome between intervention and control in by calculating a mean difference with a $95 \%$ CI. To test the null hypothesis of no difference between the study groups we used the independent samples t-test.

Secondary outcomes on a continuous scale were compared by the mean difference with $95 \%$ CIs with the independent samples t-test for hypothesis testing. Secondary outcomes on a categorical scale were compared using the risk ratio with a 95\% CI and we used the Fisher's exact test for hypothesis testing.

For data management and analyses we used MS Excel and Stata V.14 (StataCorp, College Station, TX). A two-sided p value less 0.05 was considered statistically significant.

Patients and public were not involved in the design of the study. Of course, we are indebted to the patients who participated in this study for their trust and support. This was a registered clinical trial (ClinicalTrials.gov Identifier: NCT01777750).

\section{RESULTS}

From 2013 to 2016, a total of 120 patients were formally enrolled in this trial. The intention-to-treat set consisted of 101 patients because 19 patients (16\%; hypothermia group $\mathrm{n}=12$; control group: $\mathrm{n}=7$ ) had to be excluded due to randomisation errors. Of these, 47 patients $(47 \%)$ were randomised to receive $\mathrm{MTH}$ and 54 patients (53\%) were randomised to standard treatment. The per-protocol set consisted of 39 patients in the hypothermia group and 47 patients in the control group. A flow chart and reasons for postrandomisation exclusion are presented in figure 1 .

We found no statistically significant differences in baseline and angiographic characteristics between both groups except for previous medication with statins (hypothermia group 3/47 patients $(6 \%)$; control group $12 / 54$ patients $(22 \%)$; $\mathrm{p}=0.03$, table 1). Although time from symptom onset to reperfusion was not statistically different between both groups (hypothermia group $192 \pm 67 \mathrm{~min}$; control group $180 \pm 87 \mathrm{~min}$; $\mathrm{p}=0.43$ ) study-related interventions significantly affected the time from first medical contact to reperfusion (hypothermia group $103 \pm 21 \mathrm{~min}$; control group $89 \pm 24 \mathrm{~min}$; $\mathrm{p}<0.01$ ) (figure 2). Mean tympanic temperatures at baseline were not different between both groups (hypothermia group $36.1^{\circ} \mathrm{C} \pm 0.5^{\circ} \mathrm{C}$; control group $36.0^{\circ} \mathrm{C} \pm 0.8^{\circ} \mathrm{C} ; \mathrm{p}=0.38$ ). The out-of-hospital part of temperature management could significantly reduce temperature on arrival in the cath lab from $36.1^{\circ} \mathrm{C}\left( \pm 0.5^{\circ} \mathrm{C}\right)$ to $35.5^{\circ} \mathrm{C}\left( \pm 0.6^{\circ} \mathrm{C}\right) \quad(\mathrm{p}<0.01$; paired t-test) using surface cooling and cold saline (mean $867 \pm 367 \mathrm{~mL}$ ). As mandated per protocol a temperature of $35.0^{\circ} \mathrm{C}$ or lower at reperfusion could be achieved in $38 / 47$ $(81 \%)$ in the hypothermia group. In the hypothermia group mean core temperature was $34.4^{\circ} \mathrm{C} \pm 0.6^{\circ} \mathrm{C}$ at reperfusion. Maximal blood temperature at reperfusion in the hypothermia group was $35.7^{\circ} \mathrm{C}$ (figure 3 ). 


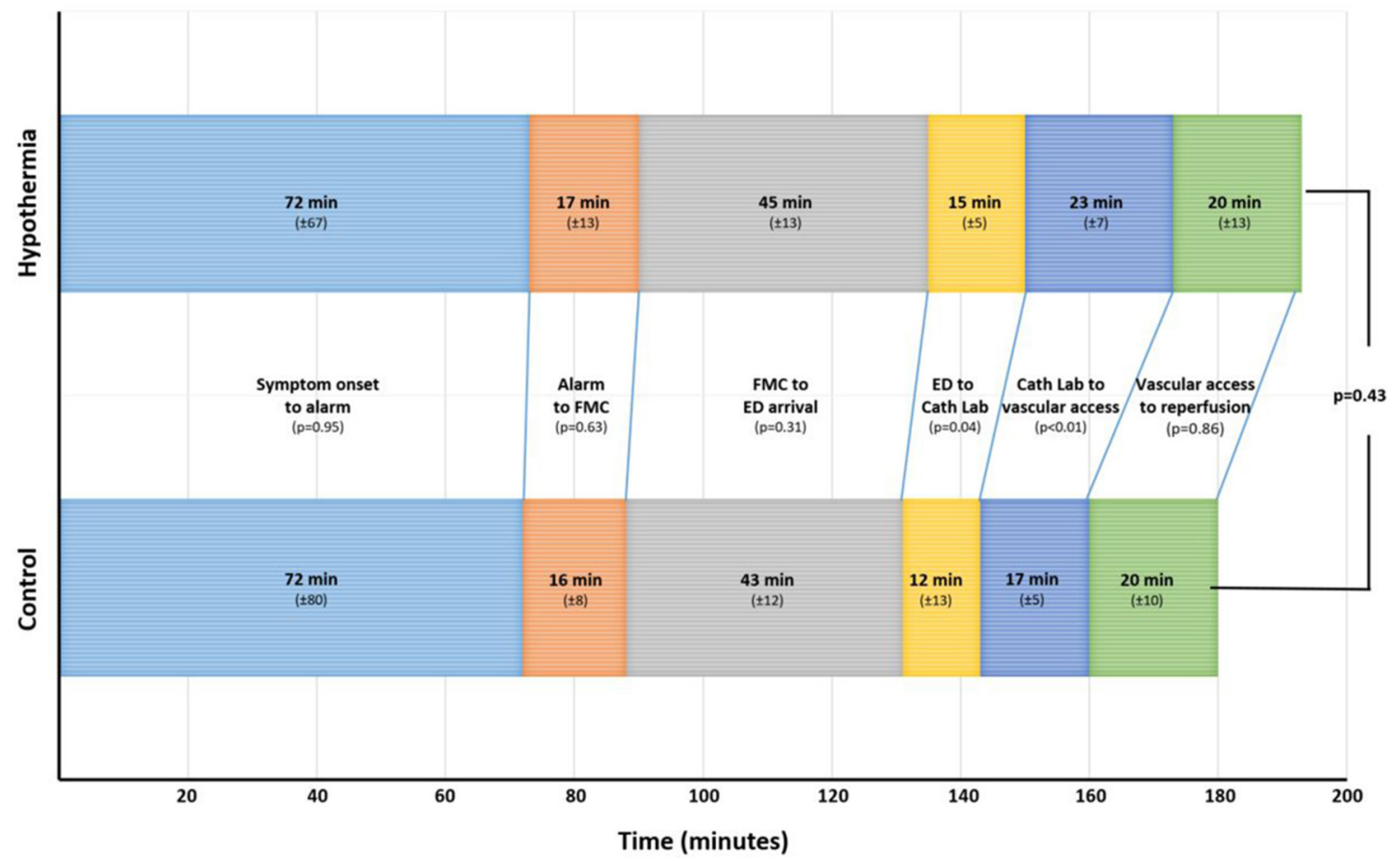

Figure 3 Box plot of temperature measurements during the study procedure. Dark squares indicate control group and white squares indicate hypothermia group. *Blood temperature (measured by the use of the endovascular cooling catheter). All other temperatures were measured tympanically. Baseline temperature was not different between the groups $(p=0.31)$. All other temperature measurements showed a significant difference between the groups (all $p<0.01$ ). 
Table 2 Cardiac MRI data

\begin{tabular}{|c|c|c|c|c|c|c|}
\hline & $\mathrm{n}$ & Control & $\mathrm{n}$ & Hypothermia & Mean difference $(95 \% \mathrm{Cl})$ & $P$ values \\
\hline \multicolumn{7}{|l|}{ Primary outcome } \\
\hline CMR, days after event mean $( \pm S D)$ & 47 & $3.6( \pm 1.3)$ & 43 & $3.6( \pm 0.9)$ & $0.03(-0.45$ to 0.51$)$ & 0.91 \\
\hline $\mathrm{MSI}$, intention-to-treat set $( \pm \mathrm{SD})$ & 47 & $0.37( \pm 0.26)$ & 41 & $0.43( \pm 0.27)$ & $-0.06(-0.17$ to 0.05$)$ & 0.27 \\
\hline MSl; per-protocol set $( \pm S D)$ & 47 & $0.37( \pm 0.26)$ & 34 & $0.46( \pm 0.26)$ & $-0.09(-0.21$ to 0.02$)$ & 0.12 \\
\hline \multicolumn{7}{|l|}{ Subgroups } \\
\hline MSI, anterior wall infarction $( \pm S D)$ & 23 & $0.33( \pm 0.30)$ & 23 & $0.41( \pm 0.27)$ & $-0.08(-0.25$ to 0.09$)$ & 0.36 \\
\hline MSI, inferior wall infarction $( \pm$ SD) & 24 & $0.41( \pm 0.21)$ & 18 & $0.46( \pm 0.27)$ & $-0.06(-0.21$ to 0.09$)$ & 0.45 \\
\hline \multicolumn{7}{|l|}{ Secondary outcomes } \\
\hline Ejection fraction day 4 , mean $\%( \pm S D)$ & 47 & $51( \pm 12)$ & 42 & $51( \pm 12)$ & $-0.1(-5.0$ to 4.9$)$ & 0.99 \\
\hline End-diastolic volume day 4 , mean $\mathrm{mL}( \pm \mathrm{SD})$ & 47 & $137( \pm 48)$ & 42 & $130( \pm 42)$ & $6.3(-12.7$ to 25.2$)$ & 0.51 \\
\hline Infarct size, mean $\mathrm{mL}( \pm \mathrm{SD})$ & 47 & $29( \pm 23)$ & 42 & $27( \pm 21)$ & $2.2(-7.1$ to 11.4$)$ & 0.64 \\
\hline Infarct size/LV myocardium, mean $\mathrm{mL}( \pm \mathrm{SD})$ & 47 & $22( \pm 15)$ & 42 & $22( \pm 14)$ & $0.9(-5.3$ to 7.0$)$ & 0.79 \\
\hline Myocardium at risk, mean $\mathrm{mL}( \pm \mathrm{SD})$ & 47 & $45( \pm 26)$ & 41 & $43( \pm 23)$ & $2.3(-8.2$ to 12.8$)$ & 0.67 \\
\hline Myocardium at risk/LV myocardium, mean $\%( \pm S D)$ & 47 & $35( \pm 16)$ & 41 & $35( \pm 16)$ & $-0.63(-7.4$ to 6.1$)$ & 0.85 \\
\hline Microvascular obstruction, mean $\mathrm{mL}( \pm \mathrm{SD})$ & 47 & $3.0( \pm 5.8)$ & 42 & $2.2( \pm 4.0)$ & 0.74 (-1.38 to 2.86$)$ & 0.49 \\
\hline Microvascular obstruction/infarct, mean \% $( \pm$ SD) & 47 & $6.7( \pm 8.7)$ & 42 & $6.4( \pm 11.0)$ & $0.38(-3.77$ to 4.53$)$ & 0.86 \\
\hline \multicolumn{7}{|l|}{ Follow-up at day $195( \pm 15)$} \\
\hline CMR, days after event mean $( \pm S D)$ & 44 & $196( \pm 4)$ & 37 & $195( \pm 6)$ & $0.7(-1.3$ to 2.8$)$ & 0.49 \\
\hline Ejection fraction day $195, \%( \pm S D)$ & 44 & $53( \pm 12)$ & 35 & $54( \pm 9)$ & $-1.3(-6.3$ to 3.6$)$ & 0.59 \\
\hline End-diastolic volume day $195, \mathrm{~mL}( \pm$ SD) & 44 & $137( \pm 42)$ & 35 & $128( \pm 43)$ & $8.8(-10.6$ to 28.1$)$ & 0.37 \\
\hline Infarct size, mean $\mathrm{mL}( \pm \mathrm{SD})$ & 41 & $16( \pm 13)$ & 35 & $15( \pm 10)$ & $0.5(-5.0$ to 6.0$)$ & 0.86 \\
\hline Infarct size/LV myocardium day $195, \%( \pm$ SD) & 41 & $13( \pm 9)$ & 35 & $14( \pm 9)$ & $-1.2(-5.4$ to 2.9$)$ & 0.55 \\
\hline
\end{tabular}

CMR, cardiac MRI; LV, left ventricular; MSI, myocardial salvage index.

\section{Secondary endpoints}

No secondary CMR outcomes were significantly different (table 2). Baseline levels of myocardial biomarkers were comparable between both groups and we found no significant difference in their time course (table 3). There were also no differences in rates of heart failure, malignant arrhythmias, reinfarction, stroke or hospital readmission up to day 45 between both groups. Whereas the use of MTH was not associated with an increased rate of sepsis and/or pneumonia rates (hypothermia group $1 / 47$ patients $(2 \%)$; control group $2 / 54$ patients $(4 \%)$; $\mathrm{p}=0.64)$ a trend towards increased bleeding events was detected in the hypothermia group (hypothermia group 11/47 patients (23\%); control group 5/54 patients (9\%); $\mathrm{p}=0.06$ ) (table 4). CMR follow-up data were available for 37 patients (79\%) in the hypothermia group and 44 patients (81\%) in the control group. Similarly, there were no significant differences between both groups (table 2).

Analyses of the per-protocol set as well as post hoc subgroup analyses are presented in the online supplementary appendix.

\section{DISCUSSION}

In this prospective, randomised, single-centre trial we could demonstrate that a protocol using out-of-hospital initiation of therapeutic hypothermia is feasible and can reduce body core temperature to $34.4^{\circ} \mathrm{C}$ with a delay of $14 \mathrm{~min}$ in the time from first medial contact to reperfusion. No safety concerns were raised. However, no statistically significant improvement in MSI

Table 3 Biochemical markers

\begin{tabular}{|c|c|c|c|c|}
\hline & Control $(n=54)$ & Hypothermia $(n=47)$ & Mean difference $(95 \% \mathrm{Cl})$ & $P$ values \\
\hline $\begin{array}{l}\text { Troponin T (baseline) } \\
\mu \mathrm{g} / \mathrm{L} \text {, mean }( \pm \mathrm{SD})\end{array}$ & $0.13( \pm 0.34)$ & $0.25( \pm 1.11)$ & $-0.12(-0.44$ to 0.20$)$ & 0.47 \\
\hline $\begin{array}{l}\text { Troponin T (peak concentration) } \\
\mu \mathrm{g} / \mathrm{L}, \text { mean }( \pm \mathrm{SD})\end{array}$ & $4.82( \pm 3.20)$ & $4.87( \pm 3.37)$ & $-0.05(-1.37$ to 1.27$)$ & 0.94 \\
\hline $\begin{array}{l}\text { Creatine kinase (baseline) } \\
\text { U/L, mean (IQR) }\end{array}$ & $236( \pm 360)$ & $202( \pm 213)$ & 24 (-16 to 64$)$ & 0.58 \\
\hline $\begin{array}{l}\text { Creatine kinase (peak concentration) } \\
U / L \text {, mean }( \pm S D)\end{array}$ & $2180( \pm 1947)$ & $2366( \pm 2146)$ & $-186(-1002$ to 630$)$ & 0.65 \\
\hline $\begin{array}{l}\text { Creatine kinase MB fraction (peak concentration) } \\
\text { U/L, mean }( \pm S D)\end{array}$ & $233( \pm 163)$ & $299( \pm 251)$ & $-65(-149$ to 19$)$ & 0.13 \\
\hline $\begin{array}{l}\text { proBNP (baseline) } \\
\text { ng/L mean }( \pm S D)\end{array}$ & $511( \pm 1454)$ & $896( \pm 3272)$ & $-385(-1389$ to 619$)$ & 0.45 \\
\hline $\begin{array}{l}\text { proBNP (on day } 4) \\
\text { ng/L, mean }( \pm S D)\end{array}$ & $1565( \pm 2667)$ & $2628( \pm 5841)$ & -1063 (-2898 to 773$)$ & 0.25 \\
\hline
\end{tabular}

proBNP, pro-brain natriuretic peptide. 


\begin{tabular}{|c|c|c|c|c|}
\hline Adverse events up to day $45 \pm 15$ & Control $(n=54)$ & Hypothermia $(n=47)$ & Risk ratio $(95 \% \mathrm{Cl})$ & $P$ values \\
\hline Death, $\mathrm{n}(\%)$ & 2 (4) & $1(2)$ & 0.57 (0.05 to 6.44$)$ & 0.64 \\
\hline VF/VT, n (\%) & $7(13)$ & $5(11)$ & 0.80 (0.24 to 2.71$)$ & 0.72 \\
\hline Stroke, n (\%) & $1(2)$ & $1(2)$ & $1.15(0.07$ to 18.94$)$ & 0.92 \\
\hline Heart failure, $\mathrm{n}(\%)$ & $3(6)$ & $3(6)$ & $1.16(0.22$ to 6.04$)$ & 0.90 \\
\hline Any bleeding, $\mathrm{n}(\%)$ & $5(9)$ & $11(23)$ & 2.99 (0.96 to 9.38$)$ & 0.06 \\
\hline Minimal bleeding, $n(\%)$ & $4(7)$ & $6(13)$ & 1.83 (0.48 to 6.92$)$ & 0.51 \\
\hline Minor bleeding, $\mathrm{n}(\%)$ & $1(2)$ & $4(8)$ & $4.93(0.53$ to 45.76$)$ & 0.18 \\
\hline Major bleeding, n (\%) & $0(0)$ & $1(2)$ & 1.02 (0.98 to 1.07$)$ & 0.47 \\
\hline Any cause hospital admission, $\mathrm{n}(\%)$ & $9(17)$ & $4(9)$ & $0.47(0.13$ to 1.62$)$ & 0.22 \\
\hline
\end{tabular}

ACBP, aortocoronary bypass; VF/VT, ventricular fibrillation/ventricular tachycardia.

as the primary outcome measure was seen by using MTH as adjunct to standard therapy in patients with STEMI.

None of the previous published trials, except of a small pilot study, detected a significant improvement of myocardial salvage in the overall group. ${ }^{14}$ This is consistent with our findings. As suggested in a subgroup analysis of the CHILL-MI trial and a recent meta-analysis, beneficial effects of MTH might be evident in patients presenting early after symptom onset with a large (especially anterior wall) infarction. ${ }^{15} 19$ A post hoc analysis of presenters within $60 \mathrm{~min}$ after symptom onset showed a significantly improved MSI in the hypothermia group in both anterior wall infarction and inferior wall infarction (see online supplementary appendix). These findings indicate that ischaemia/reperfusion injury is a time-dependent phenomenon with a declining effect of reperfusion and increasing effect of direct ischaemia. Therefore, when targeting reperfusion injury, early intervention plays a crucial role.

As shown in animal trials, the precise schedule of hypothermia is of paramount importance, mandating immediate initiation of hypothermia and achieving therapeutic levels prior to revascularisation although the optimal target temperature is still a matter of debate. ${ }^{20}$ Most previous studies already used a target temperature of $35.0^{\circ} \mathrm{C}$ at the time of reperfusion but achieving this has remained a major challenge in all clinical trials. ${ }^{15}$ Shivering was well controlled in all patients. Nevertheless, due to the initial use of surface cooling subclinical shivering might have counteracted our cooling efforts. Whereas the necessity of prereperfusion hypothermia is assumed to be proven, the duration of postreperfusion hypothermia is still unclear. In the presented protocol as well as in the CHILL-MI trial hypothermia was continued for 1 hour after reperfusion. ${ }^{15}$ In the COOL-AMI pilot study this period was extended to 3 hours and is being retained in the ongoing main COOL-AMI trial. ${ }^{12}{ }^{14}$ The ideal method of induction of hypothermia is yet unknown. All available large trials on this topic used systemic hypothermia for cardioprotection. Selective cardiac hypothermia using catheter-based infusion of cold saline beyond the infarct-related lesion might be a promising method but clinical outcome data are lacking. ${ }^{21}$

In the VELOCITY trial concerns about the safety of periprocedural MTH in STEMI arose with a significant increase in adverse events in the hypothermia group and a trend towards increased stent thrombosis. ${ }^{22}$ Whereas therapeutic hypothermia allegedly reduces the platelet inhibitory effect of P2Y12 antagonists and therefore may increase the rate of stent thrombosis ${ }^{23}$ for prasugrel, a satisfactory platelet inhibition was shown even in hypothermic patients. ${ }^{24} 25$ Corresponding to this, no increased rate of ischaemia-driven target vessel reperfusion was evident in our trial. However, treatment with therapeutic hypothermia led to a non-significant increase in bleeding events, especially minor bleedings from the arterial puncture site.

\section{Limitations}

Patient selection was aimed to include stable patients with STEMI and therefore the results are not generalisable to all patients with STEMI. In patients after cardiac arrest temperature management is already recommended by the guidelines. ${ }^{26}$

Due to the nature of our intervention blinding of patients or attending physicians was not possible. However, our primary endpoint was assessed by an independent radiologist blinded for group allocation. There is an ongoing discussion which imaging modality to use for evaluation of cardioprotective strategies. Whereas single photon emission computed tomography is the gold standard, evaluating area at risk by T2-weighted CMR for detection of oedema and LGE for detection of scar or necrosis are most widely used techniques to calculate myocardial salvage. ${ }^{27}$ MSI may be limited by the observation that postconditioning reduces the area at risk itself, ${ }^{28}$ thus this method may underestimate myocardial salvage. Nevertheless, a recent study suggests that area at risk is not affected by hypothermia in the CHILL-MI trial. ${ }^{29}$ Furthermore, MSI serves as a surrogate for strong clinical endpoints such as mortality. Due to the limited

\section{Key messages}

What is already known on this subject?

- Hypothermia in myocardial infarction provides myocardial protection in animal models. Data from clinical trials are inconsistent.

\section{What might this study add?}

- The results of this randomised clinical trial did not show a significant improvement in myocardial salvage index by the use of out-of-hospital initiation of targeted temperature management as an adjunct to primary percutaneous coronary intervention (control group: $0.37( \pm 0.26)$; hypothermia group: $0.43( \pm 0.27) ; p=0.27)$. Specific subgroup of patients may benefit from this intervention.

How might this impact on clinical practice?

- Hypothermia in myocardial infarction is currently not applicable in clinical practice. Further trials are required. 
number of patients included in our study our results are associated with a considerable risk of a statistical type 2 error.

\section{CONCLUSION}

The results of this trial did not show a significant improvement of myocardial salvage by out-of-hospital initiation of targeted temperature management as an adjunct to primary PCI. Post hoc analysis confirms the signal of previous trials that patients presenting early may benefit.

Acknowledgements The authors thank Gerhard Ruzicka (study coordinator) and E\&E CRO Consulting (Monitoring) for their excellent work. We are indebted to the patients who participated in this study for their trust and support.

Funding This work was supported by the Austrian Science Fund (APKLI209).

Competing interests None declared.

Patient consent Obtained.

Ethics approval Ethics Committee of the Medical University of Vienna (ethical committee number: 1497/2012).

Provenance and peer review Not commissioned; externally peer reviewed.

Open access This is an open access article distributed in accordance with the Creative Commons Attribution Non Commercial (CC BY-NC 4.0) license, which permits others to distribute, remix, adapt, build upon this work non-commercially, and license their derivative works on different terms, provided the original work is properly cited, appropriate credit is given, any changes made indicated, and the use is non-commercial. See: http://creativecommons.org/licenses/by-nc/4.0/.

\section{REFERENCES}

1 Ibanez B, James S, Agewall S, et al. 2017 ESC Guidelines for the management of acute myocardial infarction in patients presenting with ST-segment elevation: The Task Force for the management of acute myocardial infarction in patients presenting with ST-segment elevation of the European Society of Cardiology (ESC). Eur Heart J 2018:39:119-177.

2 Burns RJ, Gibbons RJ, Yi Q, et al. The relationships of left ventricular ejection fraction, end-systolic volume index and infarct size to six-month mortality after hospital discharge following myocardial infarction treated by thrombolysis. J Am Coll Cardiol 2002;39:30-6.

3 Yellon DM, Hausenloy DJ. Myocardial reperfusion injury. N Engl J Med 2007;357:1121-35

4 Hausenloy DJ. Conditioning the heart to prevent myocardial reperfusion injury during PPCI. Eur Heart J Acute Cardiovasc Care 2012;1:13-32.

5 Bulluck H, Yellon DM, Hausenloy DJ. Reducing myocardial infarct size: challenges and future opportunities. Heart 2016;102:341-8.

6 Götberg M, van der Pals J, Olivecrona GK, et al. Mild hypothermia reduces acute mortality and improves hemodynamic outcome in a cardiogenic shock pig model. Resuscitation 2010;81:1190-6.

7 Polderman KH. Application of therapeutic hypothermia in the intensive care unit. Opportunities and pitfalls of a promising treatment modality-Part 2: Practical aspects and side effects. Intensive Care Med 2004;30:757-69.

8 Hausenloy DJ, Yellon DM. Myocardial ischemia-reperfusion injury: a neglected therapeutic target. I Clin Invest 2013;123:92-100.

9 Herring MJ, Hale SL, Dai W, et al. Hypothermia in the setting of experimental acute myocardial infarction: a comprehensive review. Ther Hypothermia Temp Manag 2014:4:159-67.

10 Murtha LA, McLeod DD, Pepperall D, et al. Intracranial pressure elevation after ischemic stroke in rats: cerebral edema is not the only cause, and short-duration mild hypothermia is a highly effective preventive therapy. J Cereb Blood Flow Metab 2015:35:2109

11 Arrich J, Holzer M, Havel C, et al. Hypothermia for neuroprotection in adults after cardiopulmonary resuscitation. Cochrane Database Syst Rev 2016;2:CD004128.

12 Noc M, Erlinge D, Neskovic AN, et al. COOL AMI EU pilot trial: a multicentre, prospective, randomised controlled trial to assess cooling as an adjunctive therapy to percutaneous intervention in patients with acute myocardial infarction. Eurolntervention 2017:13:e531-9.

13 Götberg M, van der Pals J, Götberg M, et al. Optimal timing of hypothermia in relation to myocardial reperfusion. Basic Res Cardiol 2011;106:697-708.

14 Götberg M, Olivecrona GK, Koul S, et al. A pilot study of rapid cooling by cold saline and endovascular cooling before reperfusion in patients with ST-elevation myocardial infarction. Circ Cardiovasc Interv 2010:3:400-7.

15 Erlinge D, Götberg M, Lang I, et al. Rapid endovascular catheter core cooling combined with cold saline as an adjunct to percutaneous coronary intervention for the treatment of acute myocardial infarction. The CHILL-MI trial: a randomized controlled study of the use of central venous catheter core cooling combined with cold saline as an adjunct to percutaneous coronary intervention for the treatment of acute myocardial infarction. J Am Coll Cardiol 2014:63:1857-65.

16 Testori C, Sterz F, Delle-Karth G, et al. Strategic target temperature management in myocardial infarction-a feasibility trial. Heart 2013;99:1663-7.

17 Eitel I, de Waha S, Wöhrle J, et al. Comprehensive prognosis assessment by CMR imaging after ST-segment elevation myocardial infarction. J Am Coll Cardiol 2014:64:1217-26.

18 Eitel I, Desch S, Fuernau G, et al. Prognostic significance and determinants of myocardial salvage assessed by cardiovascular magnetic resonance in acute reperfused myocardial infarction. J Am Coll Cardiol 2010;55:2470-9.

19 Villablanca PA, Rao G, Briceno DF, et al. Therapeutic hypothermia in ST elevation myocardial infarction: a systematic review and meta-analysis of randomised control trials. Heart 2016;102:712-9.

20 Kohlhauer M, Berdeaux A, Ghaleh B, et al. Therapeutic hypothermia to protect the heart against acute myocardial infarction. Arch Cardiovasc Dis 2016;109:716-22.

21 Otterspoor LC, Van 't Veer M, Van Nunen LX, et al. Safety and feasibility of selective intracoronary hypothermia in acute myocardial infarction. Eurolntervention 2017:13:e1475-82

22 Nichol G, Strickland W, Shavelle D, et al. Prospective, multicenter, randomized, controlled pilot trial of peritoneal hypothermia in patients with ST-segment- elevation myocardial infarction. Circ Cardiovasc Interv 2015;8:e001965.

23 Ibrahim K, Christoph M, Schmeinck S, et al. High rates of prasugrel and ticagrelor non-responder in patients treated with therapeutic hypothermia after cardiac arrest. Resuscitation 2014:85:649-56.

24 Bednar F, Kroupa J, Ondrakova M, et al. Antiplatelet efficacy of P2Y12 inhibitors (prasugrel, ticagrelor, clopidogrel) in patients treated with mild therapeutic hypothermia after cardiac arrest due to acute myocardial infarction. $J$ Thromb Thrombolysis 2016;41:549-55.

25 Flierl U, Röntgen P, Zauner F, et al. Platelet inhibition with prasugrel in patients with acute myocardial infarction undergoing therapeutic hypothermia after cardiopulmonary resuscitation. Thromb Haemost 2016;115:960-8.

26 Nolan JP, Soar J, Cariou A, et al. European Resuscitation Council and European Society of Intensive Care Medicine Guidelines for Post-resuscitation Care 2015: Section 5 of the European Resuscitation Council Guidelines for Resuscitation 2015. Resuscitation 2015:95:202-22.

27 McAlindon E, Pufulete M, Lawton C, et al. Quantification of infarct size and myocardium at risk: evaluation of different techniques and its implications. Eur Heart $J$ Cardiovasc Imaging 2015;16:738-46.

28 Thuny F, Lairez O, Roubille F, et al. Post-conditioning reduces infarct size and edema in patients with ST-segment elevation myocardial infarction. J Am Coll Cardiol 2012:59:2175-81.

29 Nordlund D, Klug G, Heiberg E, et al. Multi-vendor, multicentre comparison of contrast-enhanced SSFP and T2-STIR CMR for determining myocardium at risk in ST-elevation myocardial infarction. Eur Heart J Cardiovasc Imaging 2016;17:744-53. 